\title{
Supporting Early Scientific Thinking Through Curiosity
}

\author{
Jamie J. Jirout* \\ Curry School of Education and Human Development, University of Virginia, Charlottesville, VA, United States
}

Curiosity and curiosity-driven questioning are important for developing scientific thinking and more general interest and motivation to pursue scientific questions. Curiosity has been operationalized as preference for uncertainty (Jirout and Klahr, 2012), and engaging in inquiry-an essential part of scientific reasoning-generates high levels of uncertainty (Metz, 2004; van Schijndel et al., 2018). This perspective piece begins by discussing mechanisms through which curiosity can support learning and motivation in science, including motivating information-seeking behaviors, gathering information in response to curiosity, and promoting deeper understanding through connection-making related to addressing information gaps. In the second part of the article, a recent theory of how to promote curiosity in schools is discussed in relation to early childhood science reasoning. Finally, potential directions for research on the development of curiosity and curiosity-driven inquiry in young children are discussed. Although quite a bit is known about the development of children's question asking specifically, and there are convincing arguments for developing scientific curiosity to promote science reasoning skills, there are many important areas for future research to address how to effectively use curiosity to support science learning.

Keywords: curiosity, scientific reasoning, scientific thinking, information seeking, exploration, learning

\section{SCIENTIFIC THINKING AND CURIOSITY}

Scientific thinking is a type of knowledge seeking involving intentional information seeking, including asking questions, testing hypotheses, making observations, recognizing patterns, and making inferences (Kuhn, 2002; Morris et al., 2012). Much research indicates that children engage in this information-seeking process very early on through questioning behaviors and exploration. In fact, children are quite capable and effective in gathering needed information through their questions, and can reason about the effectiveness of questions, use probabilistic information to guide their questioning, and evaluate who they should question to get information, among other related skills (see Ronfard et al., 2018 for review). Although formal educational contexts typically give students questions to explore or steps to follow to "do science," young children's scientific thinking is driven by natural curiosity about the world around them, and the desire to understand it and generate their own questions about the world (Chouinard et al., 2007; Duschl et al., 2007; French et al., 2013; Jirout and Zimmerman, 2015).

\section{What Does Scientific Curiosity Look Like?}

Curiosity is defined here as the desire to seek information to address knowledge gaps resulting from uncertainty or ambiguity (Loewenstein, 1994; Jirout and Klahr, 2012). Curiosity is often seen 
as ubiquitous within early childhood. Simply observing children can provide numerous examples of the bidirectional link between curiosity and scientific reasoning, such as when curiosity about a phenomenon leads to experimentation, which, in turn, generates new questions and new curiosities. For example, an infant drops a toy to observe what will happen. When an adult stoops to pick it up, the infant becomes curious about how many times an adult will hand it back before losing interest. Or, a child might observe a butterfly over a period of time, and wonder why it had its wings folded or open at different points, how butterflies fly, why different butterflies are different colors, and so on (see Figure 1). Observations lead to theories, which may be immature, incomplete, or even inaccurate, but so are many early scientific theories. Importantly, theories can help identify knowledge gaps, leading to new instances of curiosity and motivating children's information seeking to acquire new knowledge and, gradually, correct misconceptions. Like adults, children learn from their experiences and observations and use information about the probability of events to revise their theories (Gopnik, 2012).

Although this type of reasoning is especially salient in science, curiosity can manifest in many different types of information seeking in response to uncertainty, and is similar to critical thinking in other domains of knowledge and to active learning and problem solving more generally (Gopnik, 2012; Klahr et al., 2013; Saylor and Ganea, 2018). The development of scientific thinking begins as the senses develop and begin providing information about the world (Inhelder and Piaget, 1958; Gopnik et al., 1999). When they are not actively discouraged, children need no instruction to ask questions and explore, and the information they get often leads to further information seeking. In fact, observational research suggests that children can ask questions at the rate of more than 100 per hour (Chouinard et al., 2007)! Although the adults in a child's life might tire of what seems like relentless questioning (Turgeon, 2015), even young children can modify their beliefs and learn from the information they receive (Ronfard et al., 2018). More generally, children seek

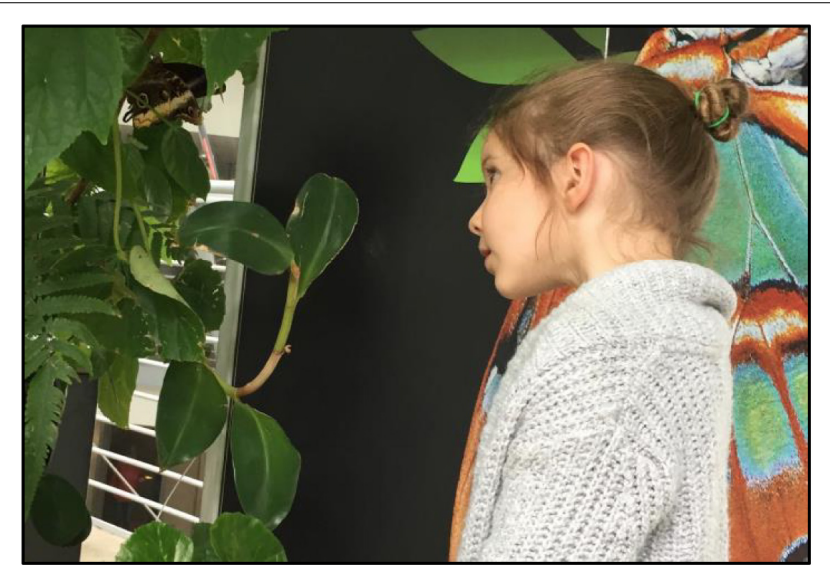

FIGURE 1 | A child looks intently at a butterfly, becoming curious about the many things she wonders based on her observations. to understand their world through active exploration, especially in response to recognizing a gap in their understanding (Schulz and Bonawitz, 2007). The active choice of what to learn, driven by curiosity, can provide motivation and meaning to information and instill a lasting positive approach to learning in formal educational contexts.

\section{How Does Curiosity Develop and Support Scientific Thinking?}

There are several mechanisms through which children's curiosity can support the development and persistence of scientific thinking. Three of these are discussed below, in sequence: that curiosity can (1) motivate information-seeking behavior, which leads to (2) question-asking and other information-seeking behaviors, which can (3) activate related previous knowledge and support deeper learning. Although we discuss these as independent, consecutive steps for the sake of clarity, it is much more likely that curiosity, question asking and information seeking, and cognitive processing of information and learning are all interrelated processes that support each other (Oudeyer et al., 2016). For example, information seeking that is not a result of curiosity can lead to new questions, and as previous knowledge is activated it may influence the ways in which a child seeks information.

\section{Curiosity as a Motivation for Information Seeking}

Young children's learning is driven by exploration to make sense of the world around them (e.g., Piaget, 1926). This exploration can result from curiosity (Loewenstein, 1994; Jirout and Klahr, 2012) and lead to active engagement in learning (Saylor and Ganea, 2018). In the example given previously, the child sees that some butterflies have open wings and some have closed wings, and may be uncertain about why, leading to more careful observations that provide potential for learning. Several studies demonstrate that the presence of uncertainty or ambiguity leads to higher engagement (Howard-Jones and Demetriou, 2009) and more exploration and information seeking (Berlyne, 1954; Lowry and Johnson, 1981; Loewenstein, 1994; Litman et al., 2005; Jirout and Klahr, 2012). For example, when children are shown ambiguous demonstrations for how a novel toy works, they prefer and play longer with that toy than with a new toy that was demonstrated without ambiguity (Schulz and Bonawitz, 2007). Similar to ambiguity, surprising or unexpected observations can create uncertainty and lead to curiosity-driven questions or explanations through adult-child conversations (Frazier et al., 2009; Danovitch and Mills, 2018; Jipson et al., 2018). This curiosity can promote lasting effects; Shah et al. (2018) show that young children's curiosity, reported by parents at the start of kindergarten, relates to academic school readiness. In one of the few longitudinal studies including curiosity, research shows that parents' promotion of curiosity early in childhood leads to science intrinsic motivation years later and science achievement in high school (Gottfried et al., 2016). More generally, curiosity can provide a remedy to boredom, giving children a goal to direct their behavior and the motivation to act on their curiosity (Litman and Silvia, 2006). 


\section{Curiosity as Support for Directing Information-Seeking Behavior}

Gopnik et al. (2015) suggest that adults are efficient in their attention allocation, developed through extensive experience, but this attentional control comes at the cost of missing much of what is going on around them unrelated to their goals. Children have less experience and skill in focusing their attention, and more exploration-oriented goals, resulting in more openended exploratory behavior but also more distraction. Curiosity can help focus children's attention on the specific information being sought (e.g., Legare, 2014). For example, when 7-9-yearold children completed a discovery-learning task in a museum, curiosity was related to more efficient learning-more curious children were quicker and learned more from similar exploration than less-curious children (van Schijndel et al., 2018). Although children are quite capable of using questions to express curiosity and request specific information (Berlyne, 1954; Chin and Osborne, 2010; Jirout and Zimmerman, 2015; Kidd and Hayden, 2015; Luce and Hsi, 2015), these skills can and should be strategically supported, as question asking plays a fundamental role in science and is important to develop (Chouinard et al., 2007; Dewey, 1910; National Governors Association, 2010; American Association for the Advancement of Science [AAAS], 1993; among others). Indeed, the National Resource Council (2012) National Science Education Standards include question asking as the first of eight scientific and engineering practices that span all grade levels and content areas.

Children are proficient in requesting information from quite early ages (Ronfard et al., 2018). Yet, there are limitations to children's question asking; it can be "inefficient." For example, to identify a target object from an array, young children often ask confirmation questions or make guesses rather than using more efficient "constraint-seeking" questions (Mills et al., 2010; Ruggeri and Lombrozo, 2015). However, this behavior is observed in highly structured problem-solving tasks, during which children likely are not very curious. In fact, if the environment contains other things that children are curious about, it could be more efficient to use a simplistic strategy, freeing up cognitive resources for the true target of their curiosity. More research is needed to better understand children's use of curiosity-driven questioning behavior as well as exploration, but naturalistic observations show that children do ask questions spontaneously to gain information, and that their questions (and follow-up questions) are effective in obtaining desired information (Nelson et al., 2004; Kelemen et al., 2005; Chouinard et al., 2007).

\section{Curiosity as Support for Deeper Learning}

Returning to the definition of curiosity as information seeking to address knowledge gaps, becoming curious-by definition-involves the activation of previous knowledge, which enhances learning (VanLehn et al., 1992; Conati and Carenini, 2001). The active learning that results from curiosity-driven information seeking involves meaningful cognitive engagement and constructive processing that can support deeper learning (Bonwell and Eison, 1991; King, 1994; Loyens and Gijbels, 2008). The constructive process of seeking information to generate new thinking or new knowledge in response to curiosity is a more effective means of learning than simply receiving information (Chi and Wylie, 2014). Even if information is simply given to a child as a result of their asking a question, the mere process of recognizing the gap in one's knowledge to have a question activates relevant previous knowledge and leads to more effective storage of the new information within a meaningful mental representation; the generation of the question is a constructive process in itself. Further, learning more about a topic allows children to better recognize their related knowledge and information gaps (Danovitch et al., 2019). This metacognitive reasoning supports learning through the processes of activating, integrating, and inferring involved in the constructive nature of curiosity-drive information seeking (Chi and Wylie, 2014). Consistent with this theory, Lamnina and Chase (2019) showed that higher curiosity, which increased with the amount of uncertainty in a task, related to greater transfer of middle school students' learning about specific science topics.

\section{PROMOTING CURIOSITY IN YOUNG CHILDREN}

Curiosity is rated by early childhood educators as "very important" or "essential" for school readiness and considered to be even more important than discrete academic skills like counting and knowing the alphabet (Heaviside et al., 1993; West et al., 1993), behind only physical health and communication skills in importance (Harradine and Clifford, 1996). Engel (2011, 2013) finds that curiosity declines with development and suggests that understanding how to promote or at least sustain it is important. Although children's curiosity is considered a natural characteristic that is present at birth, interactions with and responses from others can likely influence curiosity, both at a specific moment and context and as a more stable disposition (Jirout et al., 2018). For example, previous work suggests that curiosity can be promoted by encouraging children to feel comfortable with and explore uncertainty (Jirout et al., 2018); experiences that create uncertainty lead to higher levels of curious behavior (e.g., Bonawitz et al., 2011; Engel and Labella, 2011; Gordon et al., 2015).

One strategy for promoting curiosity is through classroom climate; children should feel safe and be encouraged to be curious and exploration and questions should be valued (Pianta et al., 2008). This is accomplished by de-emphasizing being "right" or all-knowing, and instead embracing uncertainty and gaps in one's own knowledge as opportunities to learn. Another strategy to promote curiosity is to provide support for the informationseeking behaviors that children use to act on their curiosity. There are several specific strategies that may promote children's curiosity (see Jirout et al., 2018, for additional strategies), including:

1. Encourage and provide opportunities for children to explore and "figure out," emphasizing the value of the process (exploration) over the outcome (new knowledge or skills). Children cannot explore if opportunities are 
not provided to them, and they will not ask questions if they do not feel that their questions are welcomed. Even if opportunities and encouragement are provided, the fear of being wrong can keep children from trying to learn new things (Martin and Marsh, 2003; Martin, 2011). Active efforts to discover or "figure out" are more effective at supporting learning than simply telling children something or having them practice learned procedures (Schwartz and Martin, 2004). Children can explore when they have guidance and support to engage in think-aloud problem solving, instead of being told what to try or getting questions answered directly (Chi et al., 1994).

2. Model curiosity for children, allowing them to see that others have things that they do not know and want to learn about, and that others also enjoy informationseeking activities like asking questions and researching information. Technology makes information seeking easier than it has ever been. For example, children are growing up surrounded by internet-connected devices (more than 8 per capita in 2018), and asking questions is reported to be one of the most frequent uses of smart speakers (NPREdison Research Spring, 2019). Observing others seeking information as a normal routine can encourage children's own question asking (McDonald, 1992).

3. Children spontaneously ask questions, but adults can encourage deeper questioning by using explicit prompts and then supporting children to generate questions (King, 1994; Rosenshine et al., 1996). This is different from asking "Do you have any questions?", which may elicit a simple "yes" or "no" response from the child. Instead, asking, "What questions do you have?" is more likely to provide a cue for children to practice analyzing what they do not know and generating questions. The ability to evaluate one's knowledge develops through practice, and scaffolding this process by helping children recognize questions to ask can effectively support development (Kuhn and Pearsall, 2000; Chin and Brown, 2002).

4. Other methods to encourage curiosity include promoting and reinforcing children's thinking about alternative ideas, which could also support creativity. Part of being curious is recognizing questions that can be asked, and if children understand that there are often multiple solutions or ways to do something they will be more likely to explore to learn "how we know and why we believe; e.g., to expose science as a way of knowing" (Duschl and Osborne, 2002, p. 40). Children who learn to "think outside the box" will question what they and others know and better understand the dynamic nature of knowledge, supporting a curious mindset (Duschl and Osborne, 2002).

Although positive interactions can promote and sustain curiosity in young children, curiosity can also be suppressed or discouraged through interactions that emphasize performance or a focus on explicit instruction (Martin and Marsh, 2003; Martin, 2011; Hulme et al., 2013). Performance goals, which are goals that are focused on demonstrating the attainment of a skill, can lead to lower curiosity to avoid distraction or risk to achieving the goal (Hulme et al., 2013). Mastery goals, which focus on understanding and the learning process, support learning for its own sake (Ames, 1993). When children are older and attend school, they experience expectations that prioritize performance metrics over academic and intellectual exploration, such as through tests and state-standardized assessments, which discourages curiosity (Engel, 2011; Jirout et al., 2018). In my own recent research, we observed a positive association between teachers' use of mastery-focused language and their use of curiosity-promoting instructional practices in preschool math and science lessons (Jirout and Vitiello, 2019). Among 5th graders, student ratings of teacher emphasis on standardized testing was associated with lower observed curiosity-promotion by teachers (Jirout and Vitiello, 2019). It is likely that learning orientations influence children's curiosity even before children begin formal schooling, and de-emphasizing performance is a way to support curiosity.

In summary, focusing on the process of "figuring out" something children do not know, modeling and explicitly prompting exploration and question asking, and supporting metacognitive and creative thinking are all ways to promote curiosity and support effective cognitive engagement during learning. These methods are consistent with inquiry-based and active learning, which both are grounded in constructivism and information gaps similar to the current operationalization of curiosity (Jirout and Klahr, 2012; Saylor and Ganea, 2018; van Schijndel et al., 2018). Emphasizing performance, such as academic climates focused on teaching rote procedures and doing things the "correct" way to get the right answer, can suppress or discourage curiosity. Instead, creating a supportive learning climate and responding positively to curiosity are likely to further reinforce children's information seeking, and to sustain their curiosity so that it can support scientific thinking and learning.

\section{CONCLUSION: A CALL FOR RESEARCH}

In this article, I describe evidence from the limited existing research showing that curiosity is important and relates to science learning, and I suggest several mechanisms through which curiosity can support science learning. The general perspective presented here is that science learning can and should be supported by promoting curiosity, and I provide suggestions for promoting (and avoiding the suppression of) curiosity in early childhood. However, much more research is needed to address the complex challenge of educational applications of this work. Specifically, the suggested mechanisms through which curiosity promotes learning need to be studied to tease apart questions of directionality, the influence of related factors such as interest, the impact of context and learning domain on these relations, and the role of individual differences. Both the influence of curiosity on learning and effective ways to promote it likely change in interesting and important ways across development, and research is needed to understand this development-especially through studying change in individuals over time. Finally, it is important to acknowledge that learning does not happen in isolation, and 
one's culture and environment have important roles in shaping one's development. Thus, application of research on curiosity and science learning must include studies of the influence of social factors such as socioeconomic status and contexts, the influence of peers, teachers, parents, and others in children's environments, and the many ways that culture may play a role, both in the broad values and beliefs instilled in children and the adults interacting with them, and in the influences of behavior expectations and norms. For example, parents across cultures might respond differently to children's questions, so cross-cultural differences in questions likely indicate something other than differences in curiosity (Ünlütabak et al., 2019). Although curiosity likely promotes science learning across cultures and contexts, the ways in which it does so and effective methods of promoting it may differ, which is an important area for future research to explore. Despite the benefits I present, curiosity seems to be rare or even absent from formal learning contexts (Engel, 2013), even as children show curiosity about things outside of school (Post and Walma van der Molen, 2018). Efforts to promote science learning should focus on the exciting potential for curiosity in supporting children's learning, as promoting young children's

\section{REFERENCES}

American Association for the Advancement of Science [AAAS] (1993). Benchmarks for Science Literacy. Oxford: Oxford University Press.

Ames, C. (1993). Classrooms: goals, structures, and student motivation. J. Educ. Psychol. 84, 261-271. doi: 10.1037/0022-0663.84. 3.261

Berlyne, D. E. (1954). An experimental study of human curiosity. Br. J. Psychol. 45, 256-265. doi: 10.1111/j.2044-8295.1954.tb01253.x

Bonawitz, E., Shafto, P., Gweon, H., Goodman, N. D., Spelke, E., and Schulz, L. (2011). The double-edged sword of pedagogy: instruction limits spontaneous exploration and discovery. Cognition 120, 322-330. doi: 10.1016/j.cognition. 2010.10.001

Bonwell, C. C., and Eison, J. A. (1991). Active Learning: Creating Excitement in the Classroom. 1991 ASHE-ERIC Higher Education Reports. ERIC Clearinghouse on Higher Education. Washington, DC: The George Washington University.

Chi, M. T. H., Leeuw, N. D., Chiu, M.-H., and Lavancher, C. (1994). Eliciting self-explanations improves understanding. Cogn. Sci. 18, 439-477. doi: 10.1207/ s15516709cog1803_3

Chi, M. T. H., and Wylie, R. (2014). The ICAP framework: linking cognitive engagement to active learning outcomes. Educ. Psychol. 49, 219-243. doi: 10. 1080/00461520.2014.965823

Chin, C., and Brown, D. E. (2002). Student-generated questions: a meaningful aspect of learning in science. Int. J. Sci. Educ. 24, 521-549. doi: 10.1080/ 09500690110095249

Chin, C., and Osborne, J. (2010). Supporting argumentation through students'. Questions: case studies in science classrooms. J. Learn. Sci. 19, 230-284. doi: 10.1080/10508400903530036

Chouinard, M. M., Harris, P. L., and Maratsos, M. P. (2007). Children's questions: a mechanism for cognitive development. Monogr. Soc. Res. Child Dev. 72, i-129.

Conati, C., and Carenini, G. (2001). "Generating tailored examples to support learning via self-explanation," in Proceedings of IJCAI'01, 17th International Joint Conference on Artificial Intelligence, Seattle, WA, 13011306.

Danovitch, J. H., Fisher, M., Schroder, H., Hambrick, D. Z., and Moser, J. (2019). Intelligence and neurophysiological markers of error monitoring relate to curiosity in science can start children on a positive trajectory for later learning.

\section{ETHICS STATEMENT}

Written informed consent was obtained from the individual(s) and/or minor(s)' legal guardian/next of kin publication of any potentially identifiable images or data included in this article.

\section{AUTHOR CONTRIBUTIONS}

JJ conceived of the manuscript topic and wrote the manuscript.

\section{FUNDING}

This publication was made possible through the support of grants from the John Templeton Foundation, the Spencer Foundation, and the Center for Curriculum Redesign. The opinions expressed in this publication are those of the author and do not necessarily reflect the views of the John Templeton Foundation or other funders.

Children's intellectual humility. Child Dev. 90, 924-939. doi: 10.1111/cdev. 12960

Danovitch, J. H., and Mills, C. M. (2018). "Understanding when and how explanation promotes exploration," in Active Learning from Infancy to Childhood: Social Motivation, Cognition, and Linguistic Mechanisms, eds M. M. Saylor and P. A. Ganea (Berlin: Springer), 95-112. doi: 10.1007/978-3-31977182-3_6

Dewey, J. (1910). How We Think. Lexington, MA: D.C. Heath and Company. doi: $10.1037 / 10903-000$

Duschl, R. A., and Osborne, J. (2002). Supporting and promoting argumentation discourse in science education. Stud. Sci. Educ. 38, 39-72. doi: 10.1080/ 03057260208560187

Duschl, R. A., Schweingruber, H. A., Shouse, A. W. (eds) (2007). Taking Science to School: Learning and Teaching Science in Grades K-8. Washington, DC: The National Academies Press. doi: 10.17226/11625

Engel, S. (2011). Children's need to know: curiosity in schools. Harv. Educ. Rev. 81, 625-645. doi: 10.17763/haer.81.4.h05413131647 3115

Engel, S. (2013). The Case for CURIOSITY. Educ. Leadersh. 70, 36-40.

Engel, S., and Labella, M. (2011). Encouraging exploration: the effects of teaching behavior on student expressions of curiosity, as cited in Engel, S. (2011). Children's Need to Know: curiosity in Schools. Harv. Educ. Rev. 81, 625-645. doi: 10.17763/haer.81.4.h05413131647 3115

Frazier, B. N., Gelman, S. A., and Wellman, H. M. (2009). Preschoolers' search for explanatory information within adult-child conversation. Child Dev. 80, 1592-1611. doi: 10.1111/j.1467-8624.2009.01 356.x

French, L. A., Woodring, S. D., and Woodring, S. D. (2013). Science Education in the Early Years. Handbook of Research on the Education of Young Children. Available online at: http://www.taylorfrancis.com/ (accessed February 29, 2020).

Gopnik, A. (2012). Scientific thinking in young children: theoretical advances, empirical research, and policy implications. Science 337, 1623-1627. doi: 10. 1126/science. 1223416

Gopnik, A., Griffiths, T. L., and Lucas, C. G. (2015). When younger learners can be better (or at least more open-minded) than older ones. Curr. Dir. Psychol. Sci. 24, 87-92. doi: 10.1177/0963721414556653 
Gopnik, A., Meltzoff, A. N., and Kuhl, P. K. (1999). The Scientist in the Crib: Minds, Brains, and How Children Learn. New York, NY: William Morrow \& Co.

Gordon, G., Breazeal, C., and Engel, S. (2015). Can children catch curiosity from a social robot? Proceedings of the Tenth Annual ACM/IEEE International Conference on Human-Robot Interaction, New York, NY, 91-98. doi: 10.1145/ 2696454.2696469

Gottfried, A. E., Preston, K. S. J., Gottfried, A. W., Oliver, P. H., Delany, D. E., and Ibrahim, S. M. (2016). Pathways from parental stimulation of children's curiosity to high school science course accomplishments and science career interest and skill. Int. J. Sci. Educ. 38, 1972-1995. doi: 10.1080/09500693.2016. 1220690

Harradine, C. C., and Clifford, R. M. (1996). When are children ready for kindergarten? Views of families, kindergarten teachers, and child care providers. Paper Presented at the Annual Meeting of the American Educational Research Association, New York, NY.

Howard-Jones, P. A., and Demetriou, S. (2009). Uncertainty and engagement with learning games. Inst. Sci. 37, 519-536. doi: 10.1007/s11251-008-9073-6

Heaviside, S., Farris, E., and Carpenter, J. M. (1993). Public School Kindergarten Teachers' Views on Children's Readiness for School. US Department of Education, Office of Educational Research and Improvement, National Center for Education Statistics.

Hulme, E., Green, D. T., and Ladd, K. S. (2013). Fostering student engagement by cultivating curiosity: fostering student engagement by cultivating curiosity. New Dir. Stud. Serv. 2013, 53-64. doi: 10.1002/ss.20060

Inhelder, B., and Piaget, J. (1958). The Growth of Logical Thinking from Childhood to Adolescence: An Essay on the Construction of Formal Operational Structures. London: Routledge.

Jipson, J. L., Labotka, D., Callanan, M. A., and Gelman, S. A. (2018). "How conversations with parents may help children learn to separate the sheep from the goats (and the Robots)," in Active Learning from Infancy to Childhood: Social Motivation, Cognition, and Linguistic Mechanisms, eds M. M. Saylor and P. A. Ganea (Berlin: Springer), 189-212. doi: 10.1007/978-3-319-77182-3_11

Jirout, J., and Klahr, D. (2012). Children's scientific curiosity: in search of an operational definition of an elusive concept. Dev. Rev. 32, 125-160. doi: 10.1016/ j.dr.2012.04.002

Jirout, J., and Vitiello, V. (2019). "uriosity in the classroom through supportive instruction. Paper Presented at the SRCD Biennial Meeting, Baltimore, MD.

Jirout, J., Vitiello, V., and Zumbrunn, S. (2018). "Curiosity in schools," in The New Science of Curiosity, ed. G. Gordon (Hauppauge, NY: Nova).

Jirout, J., and Zimmerman, C. (2015). "Development of science process skills in the early childhood years," in Research in Early Childhood Science Education, eds K. Cabe Trundle and M. Saçkes (Berlin: Springer), 143-165. doi: 10.1007/978-94017-9505-0_7

Kelemen, D., Callanan, M. A., Casler, K., and Pérez-Granados, D. R. (2005). Why things happen: teleological explanation in parent-child conversations. Dev. Psychol. 41, 251-264. doi: 10.1037/0012-1649.41.1.251

Kidd, C., and Hayden, B. Y. (2015). The psychology and neuroscience of curiosity. Neuron 88, 449-460. doi: 10.1016/j.neuron.2015.09.010

King, A. (1994). Guiding knowledge construction in the classroom: effects of teaching children how to question and how to explain. Am. Educ. Res. J. 31, 338-368. doi: 10.2307/1163313

Klahr, D., Matlen, B., and Jirout, J. (2013). "Children as scientific thinkers," in Handbook of the Psychology of Science, eds G. Feist and M. Gorman (New York, NY: Springer), 223-248.

Kuhn, D. (2002). "What is scientific thinking, and how does it develop?" in Blackwell Handbook of Childhood Cognitive Development, ed. U. Goswami (Oxford: Blackwell Publishing.), 371-393. doi: 10.1002/9780470996652.ch17

Kuhn, D., and Pearsall, S. (2000). Developmental Origins of Scientific Thinking. J. Cogn. Dev. 1, 113-129. doi: 10.1207/S15327647JCD0101N_11

Lamnina, M., and Chase, C. C. (2019). Developing a thirst for knowledge: how uncertainty in the classroom influences curiosity, affect, learning, and transfer. Contemp. Educ. Psychol. 59:101785. doi: 10.1016/j.cedpsych.2019.101785

Legare, C. H. (2014). The contributions of explanation and exploration to children's scientific reasoning. Child Dev. Perspect. 8, 101-106. doi: 10.1111/cdep.12070

Litman, J., Hutchins, T., and Russon, R. (2005). Epistemic curiosity, feeling-ofknowing, and exploratory behaviour. Cogn. Emot. 19, 559-582. doi: 10.1080/ 02699930441000427
Litman, J. A., and Silvia, P. J. (2006). The latent structure of trait curiosity: evidence for interest and deprivation curiosity dimensions. J. Pers. Assess. 86, 318-328. doi: 10.1207/s15327752jpa8603_07

Loewenstein, G. (1994). The psychology of curiosity: a review and reinterpretation. Psychol. Bull. 116, 75-98. doi: 10.1037/0033-2909. 116.1.75

Lowry, N., and Johnson, D. W. (1981). Effects of controversy on epistemic curiosity, achievement, and attitudes. J. Soc. Psychol. 115, 31-43. doi: 10.1080/ 00224545.1981 .9711985

Loyens, S. M., and Gijbels, D. (2008). Understanding the effects of constructivist learning environments: introducing a multi-directional approach. Inst. Sci. 36, 351-357. doi: 10.1007/s11251-008-9059-4

Luce, M. R., and Hsi, S. (2015). Science-relevant curiosity expression and interest in science: an exploratory study: CURIOSITY AND SCIENCE INTEREST. Sci. Educ. 99, 70-97. doi: $10.1002 /$ sce.21144

Martin, A. J. (2011). Courage in the classroom: exploring a new framework predicting academic performance and engagement. Sch. Psychol. Q. 26, 145160. doi: $10.1037 / \mathrm{a} 0023020$

Martin, A. J., and Marsh, H. W. (2003). Fear of Failure: Friend or Foe? Aust. Psychol. 38, 31-38. doi: 10.1080/00050060310001706997

McDonald, J. P. (1992). Teaching: Making Sense of an Uncertain Craft. New York, NY: Teachers College Press.

Metz, K. E. (2004). Children's understanding of scientific inquiry: their conceptualization of uncertainty in investigations of their own design. Cogn. Instr. 22, 219-290. doi: 10.1207/s1532690xci2202_3

Mills, C. M., Legare, C. H., Bills, M., and Mejias, C. (2010). Preschoolers use questions as a tool to acquire knowledge from different sources. J. Cogn. Dev. 11, 533-560. doi: 10.1080/15248372.2010.516419

Morris, B. J., Croker, S., Masnick, A., and Zimmerman, C. (2012). "The emergence of scientific reasoning," in Current Topics in Children's Learning and Cognition, eds H. Kloos, B. J. Morris, and J. L. Amaral (Rijeka: IntechOpen). doi: 10.5772/ 53885

National Governors Association (2010). Common Core State Standards. Washington, DC: National Governors Association.

National Resource Council (2012). A Framework for K-12 Science Education: Practices, Crosscutting Concepts, and Core Ideas. Washington, DC: National Academy Press.

Nelson, D. G. K., Chan, L. E., and Holt, M. B. (2004). When Children Ask, "What Is It? " What Do They Want to Know About Artifacts? Psychol. Sci. 15, 384-389. doi: 10.1111/j.0956-7976.2004.00689.x

NPR-Edison Research Spring (2019). The Smart Audio Report. Available online at: https://www.nationalpublicmedia.com/uploads/2019/10/The_Smart_Audio_ Report_Spring_2019.pdf (accessed February 23, 2020).

Oudeyer, P.-Y., Gottlieb, J., and Lopes, M. (2016). Intrinsic motivation, curiosity, and learning: theory and applications in educational technologies. Prog. Brain Res. 229, 257-284. doi: 10.1016/bs.pbr.2016.05.005

Piaget, J. (1926). The Thought and Language of the Child. New York, NY: Harcourt, Brace, and Company.

Pianta, R. C., La Paro, K. M., and Hamre, B. K. (2008). Classroom Assessment Scoring SystemTM: Manual K-3. Baltimore, MD: Paul H Brookes Publishing.

Post, T., and Walma van der Molen, J. H. (2018). Do children express curiosity at school? Exploring children's experiences of curiosity inside and outside the school context. Learn. Cult. Soc. Interact. 18, 60-71. doi: 10.1016/j.lcsi.2018.03. 005

Ronfard, S., Zambrana, I. M., Hermansen, T. K., and Kelemen, D. (2018) Question-asking in childhood: a review of the literature and a framework for understanding its development. Dev. Rev. 49, 101-120. doi: 10.1016/j.dr.2018. 05.002

Rosenshine, B., Meister, C., and Chapman, S. (1996). Teaching students to generate questions: a review of the intervention studies. Rev. Educ. Res. 66, 181-221. doi: $10.2307 / 1170607$

Ruggeri, A., and Lombrozo, T. (2015). Children adapt their questions to achieve efficient search. Cognition 143, 203-216. doi: 10.1016/j.cognition.2015. 07.004

Saylor, M. M., and Ganea, P. A. (eds) (2018). Active Learning from Infancy to Childhood: Social Motivation, Cognition, and Linguistic Mechanisms. Berlin: Springer. doi: 10.1007/978-3-319-77182-3 
Schulz, L. E., and Bonawitz, E. B. (2007). Serious fun: preschoolers engage in more exploratory play when evidence is confounded. Dev. Psychol. 43, 1045-1050. doi: 10.1037/0012-1649.43.4.1045

Schwartz, D. L., and Martin, T. (2004). Inventing to prepare for future learning: the hidden efficiency of encouraging original student production in statistics instruction. Cogn. Inst. 22, 129-184. doi: 10.1207/s1532690xci2 202_1

Shah, P. E., Weeks, H. M., Richards, B., and Kaciroti, N. (2018). Early childhood curiosity and kindergarten reading and math academic achievement. Pediatr. Res. 84, 380-386. doi: 10.1038/s41390-0180039-3

Turgeon, W. C. (2015). The art and danger of the question: its place within philosophy for children and its philosophical history. Mind Cult. Act. 22, 284-298. doi: 10.1080/10749039.2015.1079919

Ünlütabak, B., Nicolopoulou, A., and Aksu-Koç, A. (2019). Questions asked by Turkish preschoolers from middle-SES and low-SES families. Cogn. Dev. 52:100802. doi: 10.1016/j.cogdev.2019.100802

van Schijndel, T. J. P., Jansen, B. R. J., and Raijmakers, M. E. J. (2018). Do individual differences in children's curiosity relate to their inquiry-based learning? Int. J. Sci. Educ. 40, 996-1015. doi: 10.1080/09500693.2018.146 0772

VanLehn, K., Jones, R. M., and Chi, M. T. H. (1992). A model of the self-explanation effect. J. Learn. Sci. 2, 1-59. doi: 10.1207/s15327809jls 0201_1

West, J., Hausken, E. G., and Collins, M. (1993). Readiness for Kindergarten: Parent and Teacher Beliefs. Statistics in Brief. Available online at: https://eric.ed.gov/ ?id=ED363429 (accessed February 29, 2020).

Conflict of Interest: The author declares that the research was conducted in the absence of any commercial or financial relationships that could be construed as a potential conflict of interest.

Copyright (c) 2020 Jirout. This is an open-access article distributed under the terms of the Creative Commons Attribution License (CC BY). The use, distribution or reproduction in other forums is permitted, provided the original author(s) and the copyright owner(s) are credited and that the original publication in this journal is cited, in accordance with accepted academic practice. No use, distribution or reproduction is permitted which does not comply with these terms. 